\title{
Removal of blood amyloid- $\beta$ with hemodialysis reduced brain amyloid- $\beta$, confirmed by brain imaging: a case report
}

This article was published in the following Dove Press journal:

Neuropsychiatric Disease and Treatment

\author{
Nobuya Kitaguchi' \\ Takashi Kato ${ }^{2}$ \\ Shinji Matsunaga ${ }^{3}$ \\ Kyoko Hirano 4 \\ Kaori Iwata ${ }^{2}$ \\ Kazunori Kawaguchi' \\ Kiyoshi Fujita ${ }^{5}$ \\ Hajime Takechi ${ }^{3}$ \\ Midori Hasegawa ${ }^{4}$ \\ Yukio Yuzawa ${ }^{4}$ \\ Kengo Ito ${ }^{2}$
}

'School of Health Sciences, Fujita Health University, Toyoake, Aichi, Japan; ${ }^{2}$ Department of Brain

Science and Molecular Imaging, Research Institute, National Center for Geriatrics and Gerontology, Obu, Aichi, Japan; ${ }^{3}$ Department of Geriatrics and Cognitive Disorders, School of Medicine, Fujita Health University, Toyoake, Aichi, Japan; ${ }^{4}$ Department of Nephrology, School of Medicine, Fujita Health University, Toyoake, Aichi, Japan; ${ }^{5}$ Okehazama Hospital, Fujita Kokoro Center, Seisinkai, Toyoake, Aichi, Japan
Correspondence: Nobuya Kitaguchi School of Health Sciences, Fujita Health University, I-98 Dengakugakubo,

Kutsukake-cho, Toyoake,

Aichi 470-I I92, Japan

Tel +8I 562932657

Fax +8I 562934595

Email nkitaguc@fujita-hu.ac.jp

\begin{abstract}
The accumulation of amyloid- $\beta$ protein $(A \beta)$ in the brain signifies a major pathological change of Alzheimer's disease (AD). Extracorporeal blood A $\beta$ removal system (E-BARS) has been under development as a tool for enhancing the clearance of $A \beta$ from the brain. Previously, we revealed that dialyzers remove blood $A \beta$ s effectively, evoking substantial $A \beta$ influx into the blood during hemodialysis sessions as one form of blood $A \beta$ removal by E-BARS, and that postmortem brains of hemodialysis patients exhibited lower $A \beta$ accumulation. Here, we present a case report of a 77-year-old male patient with end-stage renal failure whose $A \beta$ accumulation in the brain declined by initiating and continuing hemodialysis for 6 months. This report suggests that blood $A \beta$ removal by E-BARS could be an effective therapeutic method for AD.
\end{abstract}

Keywords: amyloid- $\beta, \mathrm{A} \beta, \mathrm{PiB} / \mathrm{PET}$, blood purification, blood $\mathrm{A} \beta$ removal, Alzheimer's disease, E-BARS, extracorporeal blood A $\beta$ removal system

\section{Introduction}

The deposition of amyloid- $\beta$ protein $(A \beta)$ is one of the major hallmarks in the brain of Alzheimer's disease (AD). ${ }^{1}$ Of several A $\beta$ species present in the brain and plasma, 40-amino acid $A \beta_{1-40}$ and 42-amino acid $A \beta_{1-42}$ are the most prevalent. $A \beta_{1-42}$ aggregates more readily to form neurotoxic $A \beta$ oligomers. Recent findings suggested that the decreased clearance of $A \beta$ from the brain could be a mechanism for the increase of brain $\mathrm{A} \beta$, especially in sporadic $\mathrm{AD}$ cases. ${ }^{1,2}$

As a tool for enhancing the clearance of $A \beta$ from the brain, we proposed extracorporeal blood $A \beta$ removal system (E-BARS) based on our hypothesis that the rapid removal of blood $A \beta$ could facilitate peripheral $A \beta$ drainage from the brain. ${ }^{3}$ As shown in Figure 1, blood $A \beta$ s are extracorporeally removed using $A \beta$ removal devices, decreasing the concentrations of blood $A \beta s$, which might accelerate $A \beta$ transport from the brain into the blood. There are several effective $A \beta$ removal devices. We found that the most efficient materials are hexadecyl-alkylated cellulose beads ${ }^{4}$ and hollow fibers in dialyzers made of hydrophobic materials such as polysulfone and polymethylmethacrylate. ${ }^{5,6}$ These materials exhibit $A \beta$ removal efficiencies as high as $\sim 100 \%$ for both $\mathrm{A} \beta_{1-40}$ and $\mathrm{A} \beta_{1-42}$ in vitro, with enough contacting time with $\mathrm{A} \beta \mathrm{s},{ }^{4-6}$ and $50 \%$ or more in extracorporeal circulation with a blood flow of $200 \mathrm{~mL} / \mathrm{min}$, such as in hemodialysis. ${ }^{7,8}$ Adsorption is the primary $A \beta$ removal mechanism, even in dialyzers used for hemodialysis. An investigation of patients with end-stage renal failure revealed that a massive influx of $A \beta$ from certain tissues into the blood occurred during hemodialysis sessions, which removed blood $A \beta$ s as one form of blood $A \beta$ 


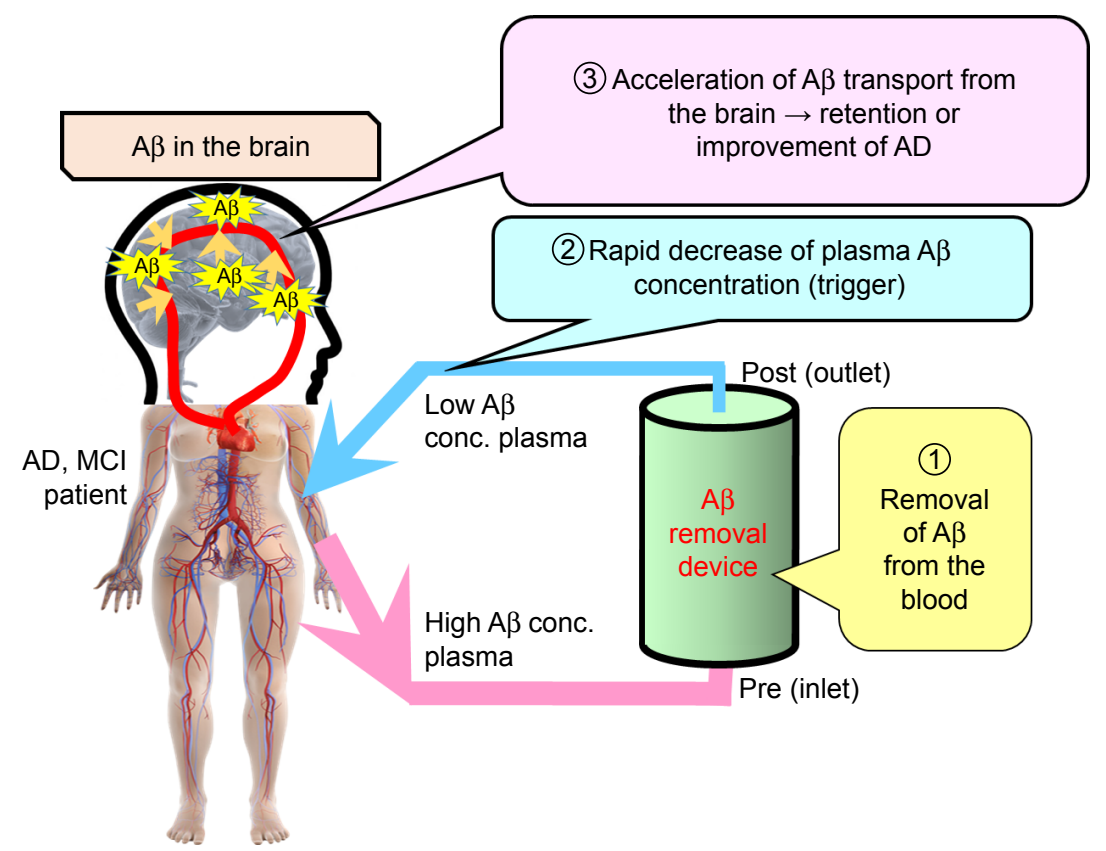

Figure I Schematic of extracorporeal blood $A \beta$ removal system.

Note: Rapid removal of blood $A \beta$ reduces $A \beta$ concentrations in the blood, which might accelerate $A \beta$ transport from the brain into the blood. Abbreviations: $A \beta$, amyloid- $\beta$ protein; $A D$, Alzheimer's disease; conc., concentration; $M C l$, mild cognitive impairment.

removal by E-BARSs. ${ }^{7-9}$ One of the origins of this large $A \beta$ influx could be the brain, based on our histopathological studies reporting that the $A \beta$ accumulation in the brains of patients undergoing hemodialysis was markedly lower than that in age-matched controls without hemodialysis. ${ }^{10}$ Furthermore, we revealed that cognitive functions of hemodialysis patients were maintained or marginally improved in a prospective study of 30 hemodialysis patients, ${ }^{9}$ and that a longer hemodialysis duration correlated with a lower dementia risk based on an analysis of over 200,000 hemodialysis patients in Japan. ${ }^{11}$

As a different method from our study to remove blood $\mathrm{A} \beta \mathrm{s}$, plasma exchange therapy (discarding plasma containing $A \beta s$, followed by the administration of albumin that is an $\mathrm{A} \beta$-binding substance) was also effective in improving cognitive functions in patients with AD. ${ }^{12}$ In addition, peritoneal dialysis, which uses patients' peritonea as dialysis membranes, reduced plasma $A \beta$ in humans and brain $A \beta$ in mouse AD models. ${ }^{13}$ Thus, the therapeutic strategy of removing blood $A \beta$ has gathered attention as the peripheral $\mathrm{A} \beta$ clearance for AD. ${ }^{14}$

However, seemingly, no direct evidence indicates that $\mathrm{A} \beta$ in the brain could be reduced by hemodialysis, which removes blood $A \beta$. The present study prospectively investigates the change in the brain $A \beta$ caused by hemodialysis in a patient with renal failure whose $A \beta$ accumulation in the brain was confirmed at the hemodialysis initiation by positron emission tomography (PET) imaging with [C-11]-(2-[4-methyl-amino phenyl]-1,3-benzothiazol-6-ol) or Pittsburgh compound $\mathrm{B}(\mathrm{PiB})$ as a probe (PiB/PET). This prospective study was approved by the Institutional Review Board at Fujita Health University (latest approval number: HM16-266); the approval included permission to publish a case report. In addition, the patient provided written informed consent to participate in this study and to have the case details and any accompanying images published.

\section{Case report}

A 77-year-old male patient with end-stage renal failure was admitted to our hospital for hemodialysis initiation. He was nondiabetic and had a 60-year smoking history from age 16 to 76 years, and had no ApoE4 ( $\varepsilon 4$ allele). His preexisting diseases were hypertension and hyperuricemia. On admission, initial investigation revealed high serum creatinine $(\mathrm{Cr} ; 8.63 \mathrm{mg} / \mathrm{dL})$ and blood urea nitrogen $(87.8 \mathrm{~g} / \mathrm{dL})$ concentrations in the patient's blood. Other results were as follows: white blood cells, 5,900/ $\mu \mathrm{L}$; hemoglobin, $9.4 \mathrm{~g} / \mathrm{dL}$; platelets, $23.7 \times 10^{4} / \mu \mathrm{L}$; total protein, $5.7 \mathrm{~g} / \mathrm{dL}$; and albumin, $2.8 \mathrm{~g} / \mathrm{dL}$. Urinalysis revealed urinary protein $(3+)$ and occult blood (1+). Ultrasonography showed atrophy of the kidneys. Although the reason for renal failure was unclear, 

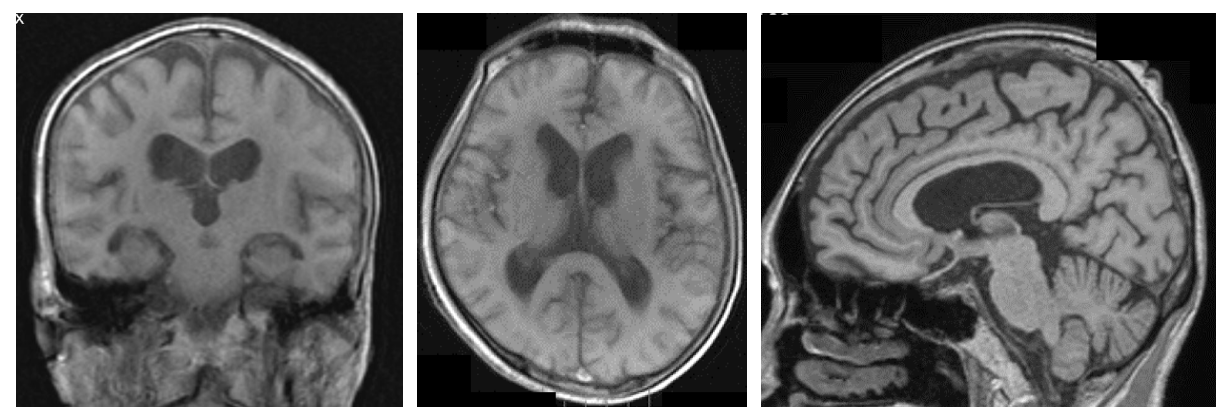

Figure $\mathbf{2}$ Images from the magnetic resonance imaging at the hemodialysis initiation. Notes: Left, coronal; middle, axial; right, sagittal.

we considered it to be nephrosclerosis. On the basis of these data, the patient was started on hemodialysis.

At the hemodialysis initiation, the patient was diagnosed with mild cognitive impairment per the criteria of Petersen et al. ${ }^{15}$ Although he exhibited mild memory impairment, he experienced no trouble in his routine life. His Mini-Mental State Examination (MMSE) score was 23 points (disorientation to time, recall, and calculation). In addition, the score of Wechsler Memory Scale-Revised was 14/50 for Logical Memory I and 13/50 for Logical Memory II (the period of his education was within 9-12 years), suggesting a score near the low border of the normal range. His score on the short Japanese version of the Geriatric Depression Scale (GDSS-J; published by Sugishita and Asada with the permission of the copyright holder ${ }^{16}$ ) was 6 , indicating mild depressives. He exhibited no abnormality in the thyroid function, and vitamin B12 and serum calcium concentration levels. Furthermore, he displayed no signs and symptoms of any other psychological disorder.

The cranial magnetic resonance imaging (MRI; Figure 2) was performed 3 days before the hemodialysis initiation. The MRI revealed no apparent atrophy, and the patient's hippocampus seemed to be normal. Regarding white matter lesions, the periventricular hyperintensity was grade 2, and deep white matter hyperintensity was grade 1 , as evaluated using the scale of Fazekas et al. ${ }^{17}$ Furthermore, the Hachinski et al's ischemic score ${ }^{18}$ of the patient was 3, suggesting a low possibility of vascular dementia. Hence, his cerebrovascular impairment was concluded as very mild and seemed not to affect his clinical symptoms.

Regarding the $\mathrm{A} \beta$ accumulation in the brain, threedimensional static PET imaging for 50-70 minute after the intravenous injection of $\mathrm{PiB}$ was conducted using a PET-computed tomography camera, Biograph True V (Siemens Healthineers, Erlangen, Germany), as reported previously. ${ }^{9} \mathrm{PiB}$ images were visually rated as $\mathrm{PiB}$-positive or PiB-negative, as described previously. ${ }^{19}$ The first PiB/PET was performed 14 days after the hemodialysis initiation (Figure 3, top), which showed a PiB-positive result. A quantitative analysis using the method of Australian Imaging, Biomarkers and Lifestyle (AIBL) ${ }^{20}$ showed 1.91 as the global standard uptake value ratio with whole cerebellum as reference $\left(\mathrm{SUVR}_{\mathrm{WCb}}\right)$. After the patient received maintenance hemodialysis (4 h/day, 3 days/week) for 6 months (visit 2), $\mathrm{PiB} / \mathrm{PET}$ was performed again. After 6-month hemodialysis, the $\mathrm{A} \beta$ accumulation in the brain was decreased (Figure 3, middle). The global SUVR ${ }_{\mathrm{wCb}}$ was 1.72 , which was lower by " 0.19 " than that of visit 1 . On visit $3, \mathrm{PiB} / \mathrm{PET}$ was performed

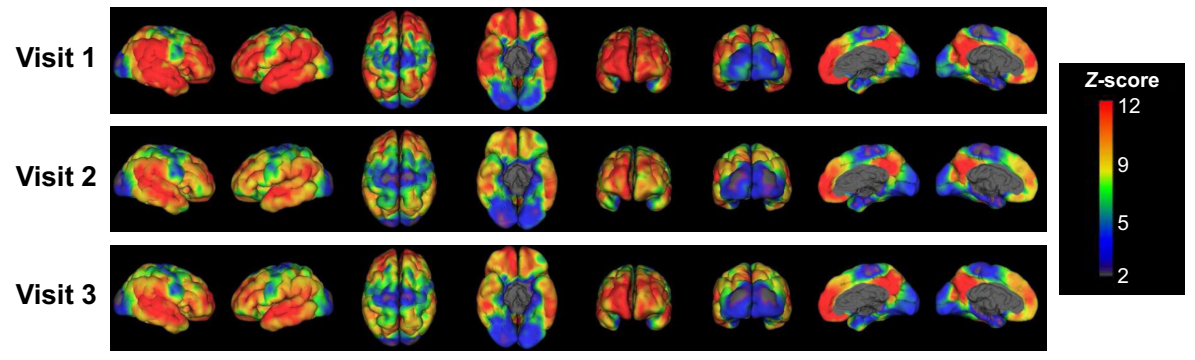

Figure 3 The SUVR ${ }_{\text {WCb }}$ image from the surface projection of PiB/PET.

Notes: Top, visit I (at the hemodialysis initiation); middle, visit 2 (6 months after the hemodialysis initiation); bottom, visit 3 ( 12 months after the hemodialysis initiation).

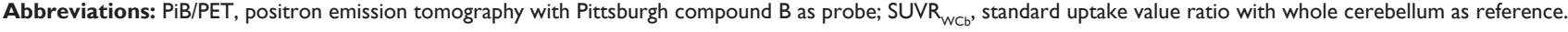


Table I PiB/PET evaluations of visits I-3

\begin{tabular}{|l|l|l|l|}
\hline \multirow{2}{*}{} & \multicolumn{3}{l|}{$\begin{array}{l}\text { Months after hemodialysis } \\
\text { initiation }\end{array}$} \\
\cline { 2 - 5 } & $\mathbf{0}$ & $\mathbf{6}$ & $\mathbf{1 2}$ \\
\hline Visual rating & Positive & Positive & Positive \\
\hline SUVR $_{\text {WCb }}$ & 1.91 & 1.72 & 1.78 \\
\hline $\begin{array}{l}\text { Change in SUVR } \\
\text { hemodialysis initiation }\end{array}$ & - & -0.19 & -0.13 \\
\hline
\end{tabular}

Abbreviations: $\mathrm{PiB} / \mathrm{PET}$, positron emission tomography with Pittsburgh compound $B$ as probe; $\mathrm{SUVR}_{\mathrm{WCb}}$, standard uptake value ratio with whole cerebellum as reference.

again after maintenance hemodialysis of 12 months (Figure 3, bottom). The global SUVR ${ }_{\mathrm{wCb}}$ was 1.78 , which was lower by " 0.13 " than that of visit 1 . The change in $\mathrm{SUVR}_{\mathrm{wCb}}$ is summarized in Table 1.

Regarding cognitive functions, MMSE scores were the lowest at 23 points at the hemodialysis initiation but gradually increased during 3 months of maintenance hemodialysis (Figure 4). Then, the scores marginally increased (improved) and were maintained at 26 points after 194 and 285 days of the hemodialysis initiation, and at 27 points after 355,453 , and 719 days (the last data are not shown in Figure 4).

We measured the concentrations of $\mathrm{A} \beta$ monomers and oligomers in the plasma, as described previously (Figure 4$).{ }^{9}$ At the hemodialysis initiation, both plasma $A \beta_{1-40}$ and $A \beta_{1-42}$ concentrations, measured with High Sensitive Human $\beta$ Amyloid (1-40) and (1-42) ELISA Kit Wako II (WAKO Pure Chemical, Osaka, Japan), were as high as 971 and $73.7 \mathrm{pg} / \mathrm{mL}$, respectively, because of renal failure. After the hemodialysis initiation, both plasma $A \beta_{1-40}$ and $A \beta_{1-42}$ concentrations decreased for around 6 months, but then increased and were maintained as 709-1,033 and 77.2-99.2 pg/mL, respectively. In addition, the ratios of $A \beta_{1-40}$ to $A \beta_{1-42}$ were 0.077 (Day 3; Figure 4) and 0.076 (Day 0) just before the hemodialysis initiation. However, the ratios increased up to 0.117 for 6 months after hemodialysis initiation, but then were maintained between 0.08 and 0.10 (Figure 4).

Contrary to $A \beta$ monomers, the concentrations of $A \beta$ oligomers in the plasma, measured with Human Amyloid $\beta$ Oligomers (82E1-specific) Assay Kit (IBL, Fujioka, Japan), were below the detection limit ( 0 ; Figure 4$)$ at the hemodialysis initiation and were maintained at 0 for 194 days after hemodialysis initiation. Then, plasma $\mathrm{A} \beta$ oligomer concentrations increased to $13.6-33.8 \mathrm{pmol} / \mathrm{L}$ after 285 days of the hemodialysis initiation (Figure 4).

Serum $\mathrm{Cr}$ and $\beta 2$-microglobulin ( $\beta 2 \mathrm{MG}$ ) concentrations just before hemodialysis sessions are shown in Figure 4 (measured by clinical test companies such as SRL, Nagoya, Japan). The change in both $\mathrm{Cr}$ and $\beta 2 \mathrm{MG}$ concentrations was small compared to $A \beta$ monomers and oligomers.

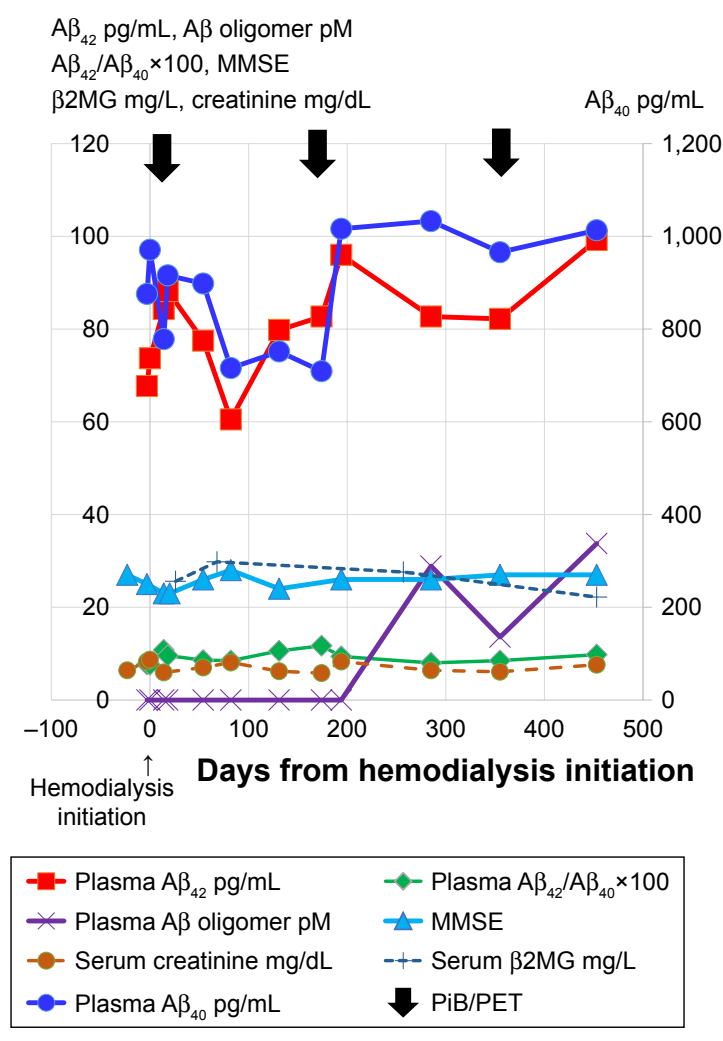

Figure 4 The concentration change of $A \beta s$ in the blood and MMSE score after the hemodialysis initiation.

Notes: The left vertical axis represents $A \beta_{L_{-42}}(\mathrm{pg} / \mathrm{mL}), A \beta$ oligomers (pmol/L), $A \beta_{\mid-42}: A \beta_{\mid-40}$ ratio $(\times 100)$, MMSE scores, $\beta 2 M G(\mathrm{mg} / \mathrm{L})$, and creatinine $(\mathrm{mg} / \mathrm{dL})$. The right vertical axis represents $A \beta_{\mid-40}(\mathrm{pg} / \mathrm{mL})$. Black arrows indicate the day of $\mathrm{PiB} / \mathrm{PET}$. The horizontal axis represents days from the hemodialysis initiation. The blood samples were collected just before the start of each hemodialysis session for the period after the hemodialysis initiation.

Abbreviations: $A \beta$, amyloid- $\beta$; $\beta 2$ MG, $\beta 2$-microglobulin; MMSE, Mini-Mental State Examination; PiB/PET, positron emission tomography with Pittsburgh compound B as probe.

\section{Discussion}

Although this study reports only one case, it is worth mentioning that 6-month hemodialysis decreased $A \beta$ in the brain by “- 0.19 SUVR” as measured by PiB/PET (Figure 3; Table 1). The reduction of " -0.19 SUVR" is comparable with that observed in a clinical study of aducanumab, where a decrease in SUVR of around 0.14 for $6 \mathrm{mg} / \mathrm{kg}$ and 0.21 for $10 \mathrm{mg} / \mathrm{kg}$ was noted after 26 weeks of administration. ${ }^{21}$

Our previous histochemical study reported that the $A \beta$ accumulation in the postmortem brains of hemodialysis patients was markedly lower than those of age-matched controls. ${ }^{10}$ Although this histochemical study was crosssectional, even 2-year hemodialysis seemed to decrease the $\mathrm{A} \beta$ accumulation in the brain; ${ }^{10}$ this finding is consistent with the finding of the present case report. Furthermore, the concentrations of both $A \beta_{1-40}$ and $A \beta_{1-42}$ in the cerebrospinal fluid decreased during the removal of blood $A \beta$ s by extracorporeal circuits with an $A \beta$ adsorbent, hexadecyl-alkylated 
cellulose beads, in a study on rats, ${ }^{22}$ this finding also supports the decrease of the $A \beta$ accumulation in the brain measured by $\mathrm{PiB} / \mathrm{PET}$ in this study.

Clinical studies of anti-A $\beta$ antibody therapy for AD revealed amyloid-related imaging abnormality (ARIA), such as microedema/microeffusion or hemosiderin deposition, as one of the adverse events to be considered. ${ }^{23}$ Because E-BARS removes blood $A \beta s$, it may remove $A \beta$ s deposited in cerebral blood vessels ${ }^{24}$ as well as in brain parenchyma. ${ }^{10}$ Therefore, ARIA could occur in hemodialysis patients. Although we did not perform follow-up MRI for this patient, we have checked for the presence or absence of ARIA-like changes in a cross-sectional study of $A \beta$ deposition in the brain slices of 17 hemodialysis patients. We did not find any ARIA-like changes, even in their brains, after 6-24 months of hemodialysis periods. Therefore, hemodialysis is less likely to cause ARIA-like changes.

Regarding the concentration change of $A \beta s$ in the blood, a study showed that the concentrations of $A \beta_{1-40}$ and $A \beta_{1-42}$ in the blood of patients with renal failure increased along with a decline of renal functions. ${ }^{8}$ Thus, the blood concentrations of $A \beta_{1-40}$ and $A \beta_{1-42}$ of our patient were very high at the hemodialysis initiation (Figure 4). After the hemodialysis initiation, which removes blood $A \beta$ effectively, both $A \beta_{1-40}$ and $A \beta_{1-42}$ decreased for about 6 months, but then increased and maintained (Figure 4); this tendency is consistent with the findings of a previous prospective study of 30 hemodialysis patients. ${ }^{9}$ The ratio of $A \beta_{1-42}$ to $A \beta_{1-40}$ increased just after the hemodialysis initiation from 0.077 to 0.108 and was sustained at around 0.10 .

The MMSE scores of our patient increased and were almost maintained at 26-28 points after 1 year of hemodialysis initiation (Figure 4); this tendency of improvement or maintenance of cognitive functions by hemodialysis, which removes blood $A \beta s$, was also observed in our previous prospective study. ${ }^{9}$ As reported recently, higher concentrations of $\mathrm{A} \beta_{1-42}$ in the blood correlate with higher cognitive functions and larger hippocampal volume. ${ }^{25}$ Furthermore, a larger ratio of $A \beta_{1-42}$ to $A \beta_{1-40}$ in the blood predicts less risk of development of $\mathrm{AD}$ and dementia. ${ }^{26}$ Based on these reports, our finding of high concentrations of blood $A \beta_{1-42}$ and a higher $A \beta_{1-42}: A \beta_{1-40}$ ratio after 6 months of hemodialysis might correlate with high MMSE scores in the same period.

Uremic toxins also cause cognitive impairment. ${ }^{27} \mathrm{Hemo-}$ dialysis can remove uremic toxins from the blood and improve cognitive functions. Cognitive impairment caused by uremia is generally worst at initiation of hemodialysis and improves in a few weeks' time. In our previous prospective study, MMSE scores were improved within just a few weeks after hemodialysis initiation. ${ }^{9}$ This short-term improvement may be attributed to removal of uremic toxins. In contrast, extracorporeal blood $A \beta$ removal might contribute to the long-term effects of hemodialysis on cognitive improvement or maintenance, as shown in this study (Figure 4), in our prospective study of 30 hemodialysis patients during 18-36 months, ${ }^{9}$ and in our cross-sectional study of over 200,000 hemodialysis patients. ${ }^{11}$

It is known that $\beta 2 \mathrm{MG}$ deposition is observed in some hemodialysis patients resulting in dialysis-related amyloidosis, which causes carpal tunnel syndrome. ${ }^{28} \beta 2 \mathrm{MG}$ is amyloidogenic but has a totally different amino acid sequence compared to $A \beta s$. Recently, hemodialyzers have been improved to enhance the efficiency of removal of blood $\beta 2 \mathrm{MG}$, resulting in fewer patients suffering from carpal tunnel syndrome. In our independent study, we found the removal efficiency of dialyzers (pre-/post-dialyzers) for $\beta 2 \mathrm{MG}$ was $\sim 50 \%$, similar to that for $\mathrm{A} \beta_{1-42}$ during hemodialysis sessions. ${ }^{29}$ The blood $\beta 2 \mathrm{MG}$ concentrations in our patient showed a small change after hemodialysis initiation compared to A $\beta s$ (Figure 4). This difference may be attributed to molecular weights $(11.8 \mathrm{kDa}$ for $\beta 2 \mathrm{MG}$ vs $\sim 4 \mathrm{kDa}$ for $A \beta$ monomers), origins (almost all nucleated cells vs neurons), influx pathway (absence vs presence of the bloodbrain barrier), absolute concentrations ( $\mathrm{mg} / \mathrm{L}$ vs $\mathrm{pg} / \mathrm{mL}$ ), and other factors such as the amounts of insoluble deposition and production rates.

According to the findings of this case report, a patient's response to the hemodialysis initiation could be divided into two phases as follows. During the first phase - from 0 to 6 months during which a decrease in SUVR can be measured by $\mathrm{PiB} / \mathrm{PET}$ - decrease in blood $\mathrm{A} \beta \mathrm{s}$ and improvement in cognitive functions are observed; during this phase, not so tightly aggregated/deposited $\mathrm{A} \beta$ s might migrate into the blood. The influx of $A \beta$ s into the blood may not be so large, resulting in marginally lower concentrations of blood $A \beta s$. The second phase - from 6 to 15 months during which no obvious change in SUVR can be shown by $\mathrm{PiB} / \mathrm{PET}$ - increase in blood $\mathrm{A} \beta \mathrm{s}$, especially $A \beta_{1-42}$, and maintenance of cognitive functions can be observed. $A \beta$ oligomers in the blood increase in this phase, may be because the influx of $A \beta$ s from the brain into the blood is gradually increased. The influx of $A \beta$ monomers into the blood may increase, because the concentrations of blood $A \beta$ monomers are high in the second phase despite high $A \beta$ removal efficiencies of dialyzers compared to the first phase. The production and clearance of $A \beta s$ in the brain almost become balanced; however, this speculation should be evaluated with a larger sample size. 
In conclusion, this case report suggests that E-BARS could be an effective therapeutic tool for AD.

\section{Acknowledgments}

The authors thank Dr Yoshiki Inui for discussing the ischemic status, and Clinical Psychologist Ms Tomoko Kitayama, Clinical Engineer Mr Shojiro Kitagawa, and Ms Miwa Sakata for their assistance. The authors also thank Dr Kazuyoshi Sakai and Mr Hiroshi Kawachi for discussion about ARIA and $\beta 2 \mathrm{MG}$, respectively. This work was partly supported by KAKENHI (20509008, 23500531, 26282126), and the Smoking Research Foundation.

\section{Author contributions}

Nobuya Kitaguchi contributed to study design, steering the study, and measurements of blood $\mathrm{A} \beta$ monomers and oligomers. Takashi Kato, Kaori Iwata, and Kengo Ito contributed to performing PiB/PET, analyzing the data of $\mathrm{PiB} / \mathrm{PET}$ and MRI, and single-photon emission computed tomography. Shinji Matsunaga and Hajime Takechi contributed to neurological diagnosis. Kyoko Hirano, Kiyoshi Fujita, Midori Hasegawa, and Yukio Yuzawa contributed to recruitment of the patient, diagnosis and treatment of renal failure, and initiation and maintenance of his hemodialysis. Kazunori Kawaguchi contributed to measurements of blood $A \beta$ monomers and oligomers. All authors contributed toward data analysis, drafting and revising the paper, gave final approval of the version to be published, and agree to be accountable for all aspects of the work.

\section{Disclosure}

Dr Kitaguchi has patents issued to this work (JP5843345 and US 10,112,000). The authors report no other conflicts of interest in this work.

\section{References}

1. Selkoe DJ, Hardy J. The amyloid hypothesis of Alzheimer's disease at 25 years. EMBO Mol Med. 2016;8(6):595-608.

2. Mawuenyega KG, Sigurdson W, Ovod V. Decreased clearance of CNS $\beta$-amyloid in Alzheimer's disease. Science. 2010;330:1774.

3. Kawaguchi K, Kitaguchi N, Nakai S, et al. Novel therapeutic approach for Alzheimer's disease by removing amyloid beta protein from the brain with an extracorporeal removal system. J Artif Organs. 2010;13(1): 31-37.

4. Kawaguchi K, Takeuchi M, Yamagawa H, et al. A potential therapeutic system for Alzheimer's disease using adsorbents with alkyl ligands for removal of blood amyloid $\beta$. J Artif Organs. 2013;16(2):211-217.

5. Kawaguchi K, Saigusa A, Yamada S, et al. Toward the treatment for Alzheimer's disease: adsorption is primary mechanism of removing amyloid $\beta$ protein with hollow-fiber dialyzers of the suitable materials, polysulfone and polymethyl methacrylate. J Artif Organs. 2016;19(2):149-158.

6. Kitaguchi N, Kawaguchi K, Yamazaki K, et al. Adsorptive filtration systems for effective removal of blood amyloid $\beta$ : a potential therapy for Alzheimer's disease. J Artif Organs. 2018;21(2):220-229.
7. Kitaguchi N, Kawaguchi K, Nakai S, et al. Reduction of Alzheimer's disease amyloid- $\beta$ in plasma by hemodialysis and its relation to cognitive functions. Blood Purif. 2011;32(1):57-62.

8. Kato M, Kawaguchi K, Nakai S, et al. Potential therapeutic system for Alzheimer's disease: removal of blood A $\beta$ s by hemodialzyers and its effect on the cognitive functions of renal-failure patients. $J$ Neural Transm. 2012;119(12):1533-1544.

9. Kitaguchi N, Hasegawa M, Ito S, et al. A prospective study on blood $\mathrm{A} \beta$ levels and the cognitive function of patients with hemodialysis: a potential therapeutic strategy for Alzheimer's disease. J Neural Transm. 2015;122(11):1593-1607.

10. Sakai K, Senda T, Hata R, et al. Patients that have Undergone Hemodialysis Exhibit Lower Amyloid Deposition in the Brain: Evidence Supporting a Therapeutic Strategy for Alzheimer's Disease by Removal of Blood Amyloid. J Alzheimers Dis. 2016;51(4):997-1002.

11. Nakai S, Wakai K, Kanda E, Kawaguchi K, Sakai K, Kitaguchi N. Is hemodialysis itself a risk factor for dementia? An analysis of nationwide registry data of patients on maintenance hemodialysis in Japan. Renal Replacement Therapy. 2018;4(1):12.

12. Boada M, Ortiz P, Anaya F, et al. Amyloid-targeted therapeutics in Alzheimer's disease: use of human albumin in plasma exchange as a novel approach for Abeta mobilization. Drug News Perspect. 2009; 22(6):325-239.

13. Jin WS, Shen LL, Bu XL, et al. Peritoneal dialysis reduces amyloid-beta plasma levels in humans and attenuates Alzheimer-associated phenotypes in an APP/PS1 mouse model. Acta Neuropathol. 2017;134(2): 207-220.

14. Wood H. Alzheimer disease: Peripheral A $\beta$ clearance - a therapeutic strategy for AD? Nat Rev Neurol. 2017;13(7):386.

15. Petersen RC, Doody R, Kurz A, et al. Current concepts in mild cognitive impairment. Arch Neurol. 2001;58(12):1985-1992.

16. Sugishita M, Asada T. Creating Geriatric Depression Scale-Short Version-Japanese, GDS-S-J. Jpn J Cognit Neurosci. 2009;11:87-90.

17. Fazekas F, Chawluk JB, Alavi A, Hurtig HI, Zimmerman RA. MR signal abnormalities at $1.5 \mathrm{~T}$ in Alzheimer's dementia and normal aging. AJR Am J Roentgenol. 1987;149(2):351-356.

18. Hachinski VC, Iliff LD, Zilhka E, et al. Cerebral blood flow in dementia. Arch Neurol. 1975;32(9):632-637.

19. Kaneko N, Nakamura A, Washimi Y, et al. Novel plasma biomarker surrogating cerebral amyloid deposition. Proc Jpn Acad Ser B Phys Biol Sci. 2014;90(9):353-364.

20. Zhou L, Salvado O, Dore V, et al. MR-less surface-based amyloid assessment based on 11C PiB PET. PLoS One. 2014;9(1):e84777.

21. Sevigny J, Chiao $P$, Bussière $T$, et al. The antibody aducanumab reduces A $\beta$ plaques in Alzheimer's disease. Nature. 2016;537(7618): $50-56$.

22. Kitaguchi N, Kawaguchi K, Kinomura J, et al. Extracorporeal Blood A $\beta$ Removal System (EBARS) reduced soluble $A \beta$ in the brain by triggering influx into the blood: rat studies. Poster presented at: Alzheimer's Association International Conference AAIC; July 17, 2017; London.

23. Salloway S, Marshall GA, Lu M, Brashear HR. Long-Term Safety and Efficacy of Bapineuzumab in Patients with Mild-To-Moderate Alzheimer's Disease: A Phase 2, Open Label Extension Study. Curr Alzheimer Res. Epub 2018 Aug 20.

24. Sakai K, Senda T, Hata R, et al. Evidence supporting a therapeutic strategy for Alzheimer's disease by removal of blood amyloid; Patients that have undergone hemodialysis exhibit lower Amyloid deposition in the brain. Poster presented at: Alzheimer's Association International Conference AAIC; July 25, 2016; Toronto.

25 . Hilal S, Wolters FJ, Verbeek MM, et al. Plasma amyloid- $\beta$ levels, cerebral atrophy and risk of dementia: a population-based study. Alzheimers Res Ther. 2018;10(1):63.

26. Koyama A, Okereke OI, Yang T, Blacker D, Selkoe DJ, Grodstein F. Plasma amyloid- $\beta$ as a predictor of dementia and cognitive decline: A systematic review and meta-analysis. Arch Neurol. 2012;69: 824-831. 
27. Bugnicourt JM, Godefroy O, Chillon JM, Choukroun G, Massy ZA. Cognitive disorders and dementia in CKD: the neglected kidney-brain axis. J Am Soc Nephrol. 2013;24(3):353-363.

28. Labriola L, Jadoul M. Dialysis-related Amyloidosis: Is It Gone or Should It Be? Semin Dial. 2017;30(3):193-196.
29. Morikawa H, Ohashi N, Kawaguchi K, et al. Potential therapeutic system for Alzheimer's disease by removal of blood $A \beta$; Efficient $A \beta$ removal system by enhancing adsorption on hollow fibers with hemodiafiltration. Poster presented at: Alzheimer's Association International Conference AAIC; July 25, 2016; Toronto.

\section{Publish your work in this journal}

Neuropsychiatric Disease and Treatment is an international, peerreviewed journal of clinical therapeutics and pharmacology focusing on concise rapid reporting of clinical or pre-clinical studies on a range of neuropsychiatric and neurological disorders. This journal is indexed on PubMed Central, the 'PsycINFO' database and CAS, and is the official journal of The International Neuropsychiatric Association (INA). The manuscript management system is completely online and includes a very quick and fair peer-review system, which is all easy to use. Visit http://www.dovepress.com/testimonials.php to read real quotes from published authors.

\footnotetext{
Submit your manuscript here: http://www.dovepress.com/neuropsychiatric-disease-and-treatment-journal
} 